\title{
Permanently Repealing the Global Gag Rule Will Internationally Advance Reproductive and Sexual Health
}

\author{
$\underline{\text { Roshni Varma }}$
}

University of California, Los Angeles, Department of Microbiology, Immunology, and Molecular Genetics, Los Angeles, CA

https://doi.org/10.38126/JSPG180114

Corresponding author: roshnivarma23@g.ucla.edu

Keywords: Global Gag Rule; abortion; foreign policy; reproductive justice; HIV/AIDS

Executive Summary: The Global Gag Rule bans foreign nongovernmental organizations (NGOs) that receive U.S. global health assistance funding from providing abortion services and referrals, advocating for abortion rights, or funding other organizations that provide abortionrelated services. The rule presents a double bind: if NGOs elect to continue providing abortionrelated care, they must forgo U.S. funding, requiring them to roll back services across the board. This reduces access to contraceptives, family planning resources, and maternal and child healthcare. The alternate option is to shut down abortion-related care to retain U.S. funding. Thus, the rule is ineffective in its purpose as it creates barriers to comprehensive sexual and reproductive healthcare, leading to increases in unintended pregnancies, abortions, and newborn and maternal death rates. In addition, restricted funding has negative implications for HIV/AIDS and reproductive cancer screening and treatment. The rule is currently implemented and repealed by each incoming president using executive orders. The United States Congress should pass the Global Health, Empowerment, and Rights Act and repeal the Helms Amendment. This will permanently revoke the Global Gag Rule and reduce unintended pregnancies, abortions, and child and maternal mortality rates across the world.

\section{Statement of issue: The Global Gag Rule}

President Ronald Reagan first enacted the Global Gag Rule in 1984 (Singh and Karim 2017, e387-e388; Barot 2017). The rule, also called the Mexico City Policy, prohibits foreign NGOs that receive U.S. global health assistance funding from providing abortion services and referrals and from advocating for abortion rights in their regions (Ahmed 2020; Kmietowicz 2019). If the NGO receives any funding from the U.S. government, the restriction also applies to funding raised from other sources (Starrs 2017, 485).

Since its initial implementation, the Global Gag Rule has been instated and revoked along partisan lines, with every Republican administration enacting the rule and every Democratic one repealing it (Tanyag
2017; The Guttmacher Institute 2009; The White House Archives 2009; Giorgio et al. 2020). The data show that by reducing funding for contraception and family planning services, the Global Gag Rule increases the number of unintended pregnancies and resulting abortions, the opposite of its intended goal (Bendavid, Avila, and Miller 2011, 873; Jones 2011). Thus, the Global Gag Rule is unnecessary and counterproductive, especially considering its adverse effects on family planning, HIV/AIDS treatment, tuberculosis treatment, nutrition, and child and maternal mortality (Singh and Karim 2017, e387e388).

\section{Implications of the Global Gag Rule}

The Global Gag Rule gives NGOs only two choices: end abortion-related care to continue receiving U.S. 
global health assistance funding or elect to forgo U.S. funding to continue providing abortion services, referrals, and advocacy. At its core, the choice is between providing comprehensive sexual and reproductive healthcare or receiving funding from the U.S. government (Tanyag 2017; Munzur-E-Murshi and Haque 2020; Ushie et al. 2020).

This binary choice is problematic for the foreign NGOs that receive U.S. global health assistance funding. The average NGO in this group relies on the U.S. government for $60 \%$ of their funding, while $26 \%$ of these NGOs rely on U.S. funding for more than $90 \%$ of their budgets (The Foundation for AIDS Research 2019). Thus, decisions regarding the Global Gag Rule substantially affect the amount of funding a foreign NGO receives. Loss of funding results in decreased ability to provide sexual and reproductive services, retain staff, continue certain programs, and support public sectors (Giorgio et al. 2020).

Because the Global Gag Rule limits access to sexual and reproductive healthcare, it has been implicated in increased instances of unintended pregnancies, increased rates of unsafe abortion, and higher maternal mortality (Bendavid, Avila, and Miller 2011, 873; Jones 2015). A study across twenty countries in sub-Saharan Africa found that abortions were 2.55 times more likely when the rule was in effect, compared to the same areas when the rule was not in effect ( $\mathrm{P}=0.01$ ) (Bendavid, Avila, and Miller 2011, 873). This is because the same NGOs that provide abortions also provide access to family planning services, including contraceptives (Tsui, McDonaldMosley, and Burke 2010, 152-153; Jones et al. 1998; World Health Organization 2019; Dreweke 2016). By reducing these resources, the Global Gag Rule leads to an increase in unwanted pregnancies and consequent abortions (Tsui, McDonald-Mosley, and Burke 2010, 152-153; Dreweke 2016; Bendavid, Avila, and Miller 2011, 873; Jones 2015; Bingenheimer and Skuster 2017).

\section{Global Gag Rule expansion: Trump administration}

The Trump administration expanded the Global Gag Rule in two ways. First, NGOs receiving U.S. assistance are now prohibited from using their finances to fund other organizations that provide abortion-related services (Open Society Foundations 2019). Secondly, the restriction now casts a wider net, applying to
NGOs receiving any kind of global health assistance funding rather than NGOs receiving specifically family planning assistance funding (Giorgio et al. 2020; Schaff et al. 2019; The White House 2017). Together, these two changes further restrict available funding for reproductive and sexual healthcare. The expansion now applies to $\$ 12$ billion of funding, as opposed to $\$ 600$ million previously, and affects NGOs in over seventy-two countries (U.S. GAO 2020).

By restricting NGOs from disseminating funding to organizations throughout their communities, the first method of expansion further hinders access to family planning and reproductive health services for women living in highly exposed areas by (Giorgio et al. 2020). More foreign NGOs, some of which are the only organizations operating in certain geographical areas, must roll back services or shut down completely due to lack of funding, creating spatial barriers to reproductive healthcare access (International Women's Health Coalition 2018). As a result, it is estimated that by 2020,1.7 million women will go without access to reproductive health services, leading to 2.1 million unintended pregnancies, 720,000 unsafe abortions, and 5,600 avoidable maternal deaths (Marie Stopes International 2018).

The expansion's second method reduces funding for NGOs that provide a broad variety of services in addition to abortion-related care, such as treatment for HIV/AIDS, tuberculosis, nutrition, child and maternal health, water sanitation and hygiene, and Zika virus (Singh and Karim 2017, e387-e388; U.S. GAO 2020; Starrs 2017; Kaiser Family Foundation 2016). Effects of the expansion are already being seen: in the Gaza Province in Mozambique, where the HIV prevalence rate is $24.1 \%$, the number of people tested for HIV dropped from 5,981 to 671 over three months following the implementation of the Global Gag Rule (Center for Health and Gender Equity 2018). Globally, it is estimated that by $2020,725,000$ people will lose access to HIV testing, and 275,000 pregnant women living with HIV will lose access to antiretroviral drug therapy (International Planned Parenthood Federation 2017).

\section{Benefits of permanently repealing the Global Gag Rule}

Repealing the Global Gag Rule will allow foreign NGOs to provide comprehensive sexual and reproductive 
healthcare. NGOs offering family planning services can continue to receive U.S. funding without having to stop providing abortion-related care. This will ultimately reduce the number of unintended pregnancies and subsequent abortions (Marie Stopes International 2018; Bendavid, Avila, and Miller 2011, 873; Jones 2011). Additionally, these same organizations can use their funding to continue to provide other vital services such as screening and treatment for HIV/AIDS, screening for reproductive cancers, and maternal and child healthcare (Planned Parenthood Global). For this reason, it is estimated that fully investing in family planning services through the repeal of the Global Gag Rule would reduce maternal deaths by nearly $75 \%$, from 308,000 to 84,000 annually. In addition, newborn deaths would fall from 2.7 million to 541,000 annually (Barot 2017). Thus, the repeal of the Global Gag Rule would contribute to reducing disparities and improving health outcomes for women and children around the world.

In addition to the intended positive effects on reproductive and sexual healthcare, providing access to abortions has a range of other societal benefits. Reproductive rights are vital to addressing other social, economic, and political factors that create disadvantages and disparities for marginalized populations (Shaw and Faúndes 2006, 300-302; National Women's Law Center 2020). Choosing when to have children opens the door for women to choose in other aspects of their life-such as pursuing secondary education or job and entrepreneurship opportunities (Barot 2017). Removing barriers for women to enter the marketplace directly leads to increased productivity and economic growth (Starbird, Norton, and Marcus 2016, 191; Habumuremyi and Zenawi 2012, 79; Barot 2017).

\section{Policy options}

The United States Congress should pass legislation that allows foreign NGOs that receive U.S. funding to continue providing abortion services, referrals, and advocacy. This will permanently repeal the Global Gag Rule.

i. Option I: Pass the Global Health, Empowerment, and Rights (HER) Act

The Global HER Act was introduced in both the House of Representatives and Senate in early 2019 but was not adopted (Ahmed 2020). Passing the Act would allow foreign NGOs to use funding raised from nonU.S. government sources to provide full access to abortion services, referral, and advocacy, directly combatting the Global Gag Rule (Boonstra 2019).

\section{Advantages}

- There will be a net increase in funding for sexual and reproductive resources flowing into nations where foreign NGOs operate.

- Harmful effects of the Global Gag Rule (e.g., increases in maternal and child mortality, unintended pregnancies, unsafe abortions) will be partially alleviated (Barot 2017).

\section{Disadvantages}

- Foreign NGOs will still be banned from using U.S. government funding for abortion-related care, thus not fully combating the harms of the Global Gag Rule.

\section{ii. Option II: Repeal the Helms Amendment}

The Helms Amendment was passed in 1973 and prohibits organizations from using U.S. funding to provide abortion services abroad, with few exceptions (Ahmed 2020; Dennis 2020). The Helms Amendment is a relic of the past, the effects of which are magnified now as countries continue to expand the legal grounds upon which women can access abortions (Center for Reproductive Rights 2019). Repealing the Helms Amendment will directly combat harms of the Global Gag Rule.

\section{Advantages}

- Foreign NGOs will be allowed to use U.S. government funding to provide access to sexual and reproductive healthcare, including abortions. This will assist in alleviating the negative effects of the Global Gag Rule.

- As more countries legalize abortion in various cases, the population of women affected by the Global Gag Rule is increasing. Repealing the Helms Amendment will provide full access to sexual and reproductive healthcare. 


\section{Disadvantages}

- Repealing the Helms Amendment alone may be insufficient to address the unquantified "chilling effect" caused by decades of contradictory abortion policy applied by the United States. Many NGOs fear retribution from future administrations and are left unclear on what is permissible under law (Global Justice Center 2018).

\section{Final recommendation: permanent repeal of the Global Gag Rule by Congress}

Revoking the Global Gag Rule is a priority to safeguard reproductive rights and reduce unintended pregnancies, abortions, and child and maternal mortality rates. The United States Congress can accomplish this by either enacting Option I, reintroducing and adopting the Global HER Act, or Option II, repealing the Helms Amendment.

\section{References}

Ahmed, Zara. 2020. "The Unprecedented Expansion of the Global Gag Rule: Trampling Rights, Health and Free Speech." The Guttmacher Institute. April 28, 2020.

https://www.guttmacher.org/gpr/2020/04/unp recedented-expansion-global-gag-rule-tramplingrights-health-and-free-speech

Barot, Sneha. 2017. "The Benefits of Investing in International Family Planning-and the Price of Slashing Funding." The Guttmacher Institute. August 1, 2017.

https://www.guttmacher.org/gpr/2017/08/ben efits-investing-international-family-planningand-price-slashing-funding\#

Bendavid, Eran, Patrick Avila, and Grant Miller. 2011. "United States aid policy and induced abortion in sub-Saharan Africa." Bulletin World Health Organization 89 (12): 873-880C. https://dx.doi.org/10.2471\%2FBLT.11.091660

Bingenheimer, Jeffrey B., and Patty Skuster. 2017. "The Foreseeable Harms of Trump's Global Gag Rule." Studies in Family Planning 48 (3). https://doi.org/10.1111/sifp.12030

Boonstra, Heather D. 2019. "The Global HER Act Would Repeal the Harmful Global Gag Rule." The Guttmacher Institute. February 7, 2009. https://www.guttmacher.org/article/2019/02/g lobal-her-act-would-repeal-harmful-global-gag$\underline{\text { rule }}$
The Global HER Act will allow foreign NGOs to use their own funding to provide abortion-related services, while repealing the Helms Amendment will strike down an old relic and allow U.S. funding to be used for abortion-related care abroad. Alone or in unison, these actions will provide access to a larger array of sexual and reproductive healthcare measures for those who need them.

The Global Gag Rule is counterproductive in reducing the abortion rate and causes collateral damage by reducing access to other important health services, such as family planning, screening and treatment for HIV/AIDS, and screening for reproductive cancers. Considering that the data shows that having the rule in place does not decrease the number of abortions and that the majority of Americans (54\%) support access to abortions for women around the globe, these recommendations should receive bipartisan support in Congress (Ahmed 2020).

Center for Health and Gender Equity. 2018. "Prescribing Chaos in Global Health: The Global Gag Rule From 1984-2018." June 2018.

https://srhrforall.org/download/prescribingchaos-in-global-health-the-global-gag-rule-from$\underline{1984-}$

2018/?wpdmdl=1064\&refresh $=5 f 73775 \mathrm{~d} 105 \mathrm{c} 41$ $\underline{601402717}$

Center for Reproductive Rights. n.d. "The World's Abortion Laws." Accessed January 2021.

https://reproductiverights.org/worldabortionla $\underline{\text { ws }}$

Dennis, Rebecca. 2020. "The Helms Amendment: You Should Have Been Gone by Now." PAI. July 30, 2020.

https://pai.org/resources/the-helmsamendment-you-should-have-been-gone-bynow/

Dreweke, Joerg. 2016. "New Clarity for the U.S. Abortion Debate: A Steep Drop in Unintended Pregnancy Is Driving Recent Abortion Declines." The Guttmacher Institute. March 18, 2016. https://www.guttmacher.org/gpr/2016/03/new -clarity-us-abortion-debate-steep-dropunintended-pregnancy-driving-recent-abortion

Giorgio, Margaret, Fredrick Makumbi, Simon Peter Sebina Kibira, Suzanne Bell, Selena Anjur-Dietrich, and Elizabeth Sully. 2020. "Investigating the early impact of the Trump Administration's Global Gag Rule on sexual and reproductive health service delivery in Uganda." PLoS ONE 15 (4): e0231960. https://doi.org/10.1371/journal.pone.0231960 
Global Justice Center. 2018. "FAQ: How US Abortion Restrictions on Foreign Assistance, including the Global Gag Rule, Violate Women's Rights \& Human Rights." January 2018.

https://globaljusticecenter.net/files/FAQAbortio nRestrictions.pdf

Habumuremyi, Perre Damien, and Meles Zenawi. 2012. "Making family planning a national development priority." The Lancet 380 (9837): 78-80. https://doi.org/10.1016/S0140-6736(12)60904$\underline{0}$

International Women's Health Coalition. 2018. "Reality Check: Year One Impact of Trump's Global Gag Rule." Accessed February 2021.

https://iwhc.org/wpcontent/uploads/2018/05/GGR-FormattedReport FINAL.pdf

International Planned Parenthood Federation. 2017. "The Human Cost of the Global Gag Rule." February 9, 2017.

https://www.ippf.org/news/human-cost-globalgag-rule

Jones, Kelly M. 2011. "Evaluating the Mexico city policy: How US foreign policy affects fertility outcomes and child health in Ghana." International Food Policy Research Institute.

https://www.ifpri.org/publication/evaluatingmexico-city-policy

Jones, Kelly M. 2015. "Contraceptive Supply and Fertility Outcomes: Evidence from Ghana." Economic Development Cultural Change 64 (1): 31-69. https://doi.org/10.1086/682981

Kaiser Family Foundation. 2020. "The Mexico City Policy: An Explainer." November 4, 2020. https://www.kff.org/global-health-policy/factsheet/mexico-city-policy-explainer/

Kmietowicz, Zosia. 2019. "Abortion: US 'global gag rule' is killing women and girls, report says." BMJ 365: I4118. https://doi.org/10.1136/bmj.14118

Marie Stopes International. n.d. "A World Without Choice: The Global Gag Rule." Accessed November 2020. https://www.mariestopes-us.org/mexico-citypolicy/

Munzur-E-Murshid and Mainul Haque. 2020. "The Global Gag Rule: The death trap for comprehensive sexual and reproductive healthcare and way to overcome the US gag rule." Journal of Population Therapeutics \& Clinical Pharmacology 27 (2). https://iptcp.com/index.php/iptcp/article/view/ $\underline{677}$

National Women's Law Center. n.d. "Reproductive Justice." Accessed November 2020. https://nwlc.org/issue/reproductive-justice/
Open Society Foundations. 2019. "What is the Global Gag Rule?" April 2019.

https://www.opensocietyfoundations.org/explai ners/what-global-gag-

rule\#: :text=The $\% 20$ global $\% 20$ gag $\% 20$ rule $\% 20$ prohibits,own \%2C\%20non\%2DU.S.\%20funds.

Planned Parenthood Global. n.d. "Assessing the Global Gag Rule: Harms to Health, Communities, and Advocacy." Accessed November 2020.

https://www.plannedparenthood.org/uploads/fi ler public/81/9d/819d9000-5350-4ea3-b6991f12d59ec67f/181231-ggr-d09.pdf

Schaff, Marta, Emily Maistrellis, Hana Thomas, Bergen Cooper, and The GGR Research Working Group. 2019. "Protecting Life in Global Health Assistance'? Towards a framework for assessing the health systems impact of the expanded Global Gag Rule." BMJ Global Health 4 (5): e001786. http://dx.doi.org/10.1136/bmigh-2019-001786

Shaw, Dorothy and Anibal Faúndes. 2006. "What is the relevance of women's sexual and reproductive rights to the practicing obstetrician/gyneacologist?" Best Practice \& Research Clinical Obstetrics \& Gynaecology 20 (3): 299-309. https://doi.org/10.1016/j.bpobgyn.2006.01.013

Singh, Jerome A and Salim S. Abdool Karim. 2017. "Trump's 'global gag rule': implications for human rights and global health." The Lancet: Global Health 5 (4): E387-E389. https://doi.org/10.1016/S2214-109X(17)30084$\underline{0}$

Starbird, Ellen, Maureen Norton, and Rachel Marcus. "Investing in Family Planning: Key to Achieving the Sustainable Development Goals." Global Health: Science and Practice 4 (2): 191-210. https://doi.org/10.9745/GHSP-D-15-00374

Starrs, Ann. 2017. "The Trump global gag rule: an attack on US family planning and global health aid." The Lancet 389 (10068): 485-486. https://doi.org/10.1016/S0140-6736(17)30270$\underline{2}$

Tanyag, Maria. 2017. "Global Gag Rule and the Political Economy of Sexual and Reproductive Freedoms." Australian Institute of International Affairs. March 27, 2017.

https://www.internationalaffairs.org.au/newsitem/global-gag-rule-and-the-political-economyof-sexual-and-reproductive-freedoms/\# ftn3

The Foundation for AIDS Research. 2019. "The Effect of the Expanded Mexico City Policy on HIV/AIDS Programming: Evidence from the PEPFAR Implementing Partners Survey." Accessed November 2020.

https://www.amfar.org/uploadedFiles/ amfaror g/Articles/On The Hill/2019/IB-1-31-19a.pdf 
The Guttmacher Institute. 2009. "Obama Rescinds 'Global Gag Rule', Commits to Funding UNFPA." January 23, 2009.

https://www.guttmacher.org/article/2009/01/o bama-rescinds-global-gag-rule-commits-fundingunfpa

The White House. 2017. "Presidential Memorandum Regarding the Mexico City Policy." Presidential Memoranda: Law \& Justice. January 23, 2017. https://trumpwhitehouse.archives.gov/presiden tial-actions/presidential-memorandumregarding-mexico-city-policy/

Office of the Press Secretary. 2009. "Statement of President Barack Obama on Rescinding the Mexico City Policy." The White House. January 23, 2009. https://obamawhitehouse.archives.gov/thepress-office/statement-president-barack-obamarescinding-mexico-city-policy

Tsui, Amy O., Raegan McDonald-Mosley, and Anne E. Burke. 2010. "Family Planning and the Burden of Unintended Pregnancies." Epidemiologic Reviews 31 (1): 152-174.

https://doi.org/10.1093/epirev/mxq012
U.S. Government Accountability Office. 2020. "Global Health Assistance: Awardees' Declination of U.S. Planned Funding Due to Abortion-Related Restrictions." GAO. March 2020. https://www.gao.gov/assets/710/705388.pdf

Ushie, Boniface Ayanbekongshie, Kenneth Juma, Grace Kimemia, Maggie Magee, Emily Maistrellis, Terry McGovern, and Sara E. Casey. 2020. "Foreign assistance or attack? Impact of the expanded Global Gag Rule on sexual and reproductive health and rights in Kenya." Sexual and Reproductive Health Matters 28 (3). https://doi.org/10.1080/26410397.2020.17944 $\underline{12}$

World Health Organization. 2019. "High rates of unintended pregnancies linked to gaps in family planning services: New WHO study." October 25, 2019.

https://www.who.int/news/item/25-10-2019high-rates-of-unintended-pregnancies-linked-togaps-in-family-planning-services-new-who-study

Roshni Varma is an undergraduate student pursuing a B.S. in Microbiology, Immunology, and Molecular Genetics at the University of California, Los Angeles. She is dedicated to improving health equity on a global scale by pursuing research at the intersection of healthcare and public policy. Roshni is also involved in legislative and clinical efforts to achieve the same goal. 